\title{
Corrientes es guaraní Análisis de representaciones en torno al guaraní antes y después de su oficialización (ley $5598 / 2004)$
}

\section{Mónica M. Medinaํㅗㄹ Adriana A. Zurlo² y Lorena Cayré Baito 3}

1 Instituto de Investigaciones Geohistóricas-CONICET/UNNE, Resistencia (Argentina)
Correo electrónico: mariselmedina@gmail.com

2 Instituto de Investigaciones Geohistóricas-CONICET/UNNE, Resistencia (Argentina) Correo electrónico: adrianazurlo@gmail.com

3 Instituto de Investigaciones Geohistóricas-CONICET/UNNE, Resistencia (Argentina)

Correo electrónico: lorena.cayrebaito@gmail.com
Recibido:

mayo de 2019

Aceptado:

Noviembre de 2019

doi: 10.34096/runa.v41i2.5904

Palabras clave

Este artículo analiza, desde una perspectiva sociolingüística, representaciones en torno al guaraní, manifiestas en distintos discursos públicos enunciados entre 2004 y 2017. El corpus reúne entrevistas a funcionarios públicos, encuestas a ciudadanos correntinos (hablantes y no hablantes de guaraní), así como también artículos periodísticos y notas de opinión publicadas en distintos medios gráficos de la región y de Corrientes. En esta muestra heterogénea se observan representaciones contradictorias sobre el guaraní que permiten cuestionar las políticas lingüísticas previas de castellanización. La estrategia de contraposición permite cuestionar y resignificar las representaciones estigmatizantes, adjudicadas al pasado, para configurar un nuevo ideal: el guaraní como parte esencial de la identidad correntina. Esta nueva representación permite construir un contradiscurso hegemónico a favor del rescate y promoción de esta lengua y también legitimar el proyecto de oficialización del guaraní, inicio de una nueva política lingüística y educativa.

\section{Corrientes es guaraní. Representations of guaraní: an analysis before and after its officialization (law 5598/2004)}

\begin{abstract}
This paper analyzes from a sociolinguistic point of view, representations of Guaraní language expressed in different public speeches enunciated between 2004 and 2017. The data consists of interviews with civil servants, surveys of Corrientes citizens (Guarani speakers and non speakers), journal articles and
\end{abstract}

Ley 5598; Lengua oficial alternativa; Representaciones sociolingüísticas; Políticas lingüísticas; Guaraní

\section{Key words}

Ley 5598; Lengua oficial alternativa; Representaciones sociolingüísticas; Políticas lingüísticas; Guaraní 
opinion pieces published in several graphic media of Corrientes. Contradictory representations of Guaraní found in this heterogeneous sample allow questioning previous castillianizing linguistic policies. Contrast strategy allows questioning and resignifying stigmatizing representations from the past and configuring a new ideal: Guarani as an essential part of Corrientes identity. This new representation allow constructing an hegemonic counterdiscourse in favor of the rescue and promotion of Guarani as well as in favor of legitimization Guarani officialization project, the beginning of a new linguistic and educative policy.

\section{Corrientes e guaraní. Representações da língua guarani: uma análise antes e depois da oficialização (lei $\left.N^{\circ} 5598 / 2004\right)$}

\section{Resumo}

Palavras-chave

Lei 5598; Língua oficial alternativa; Representações sociolinguísticas; Políticas linguísticas; Guarani
O artigo analisa, a partir da perspectiva sociolinguista, as representações da língua Guarani manifestas em diferentes discursos públicos enunciados entre os anos 2004 e 2017. O corpus reúne entrevistas a funcionários públicos, entrevistas a cidadãos correntinos (falantes e não falantes do Guarani), artigos jornalísticos e notas de opiniões publicadas em diferentes meios gráficos da região e de Corrientes. Nesta amostra heterogênea, observam-se as representações contraditórias do Guarani que permitem questionaras políticas linguísticas prévias da castelhanização. A estratégia de contraposição permite questionar e ressignificar as representações estigmatizadas do passado, configurando um ideal novo: o Guarani como parte essencial da identidade Correntina. Essa nova representação permite construir um contradiscurso hegemônico a favor do resgate e da promoção desta língua e, também, legitimar o projeto da oficialização do Guarani, iniciando uma nova política linguística e educativa.

\section{Introducción}

En el 2004 se sanciona la Ley $N^{\circ} 5598$ que declara el guaraní como lengua oficial alternativa en la provincia de Corrientes; asimismo, establece su enseñanza obligatoria en las escuelas, la creación de órganos de fomento de la literatura y cultura local, entre otras medidas tendientes a visibilizar la lengua.

El objetivo de este artículo es analizar representaciones en torno del guaraní manifiestas en distintos discursos públicos enunciados entre 2004 y 2017.En este período de tiempo nos interesa observar cómo se (re)producen imágenes y representaciones sobre el guaraní, con el fin de construir y consolidar un contradiscurso hegemónico (Bein, 2010a) a favor del rescate y promoción de esta lengua y, a la vez, deslegitimar la política lingüística vigente desde la época colonial, cuyo objetivo central era la sustitución del guaraní en favor del castellano.

El corpus reúne entrevistas a funcionarios públicos, encuestas a ciudadanos correntinos (hablantes y no hablantes de guaraní), así como también artículos 
periodísticos y notas de opinión publicadas en distintos medios gráficos de la región y de Corrientes. Esta heterogeneidad de discursos ${ }^{1}$ permite observar la coexistencia en tensión de representaciones contradictorias en torno al guaraní, que es caracterizado simultáneamente, por ejemplo, como "lengua madre de los correntinos" o como "dialecto de indios, menchos y tapes". El análisis de las representaciones sobre el guaraní, desde una perspectiva sociolingüística (Bein, 2004, 2010a y 2010b; Arnoux y Del Valle, 2010), nos permite observar el surgimiento de una nueva política lingüístico-educativa, ${ }^{2}$ favorecida por ciertas condiciones históricas del contexto regional, nacional e internacional. Este proyecto de rescate del guaraní busca legitimidad, al resignificar antiguas representaciones negativas sobre el guaraní y configurarse en torno a un nuevo ideal lingüístico: el guaraní como parte de la identidad o del ser correntino.

Después de esta introducción, el artículo continúa con una nota sociolingüística sobre el guaraní en Corrientes y con un apartado teórico-metodológico en el cual se define el concepto de representaciones y el procedimiento de análisis. En el siguiente apartado se analizan las representaciones en torno al guaraní, presentando en primer lugar el contenido de la Ley 5598 y su contextualización histórico-política; es decir, se mencionan los lineamientos centrales de las políticas lingüístico-educativas vigentes hasta ese momento y, en especial, las condiciones históricas contemporáneas a la sanción de la ley, que impulsan este giro en las políticas implementadas en el ámbito provincial. En segundo lugar, se identifican las representaciones más frecuentes del corpus, que, a fines expositivos, han sido agrupadas en tres ejes principales: a) sobre el estatus lingüístico; b) sobre categorías identitarias; y c) sobre la relación guaraníescuela. Finalmente, en las conclusiones se retoman los aportes del trabajo y se plantean algunos desafíos para la etapa de implementación de esta nueva política lingüístico-educativa provincial.

\section{Breve nota sobre la situación sociolingüística del guaraní en Corrientes}

De acuerdo con Censabella (2009), la familia tupí-guaraní comprende en el territorio argentino cuatro lenguas: ava-guaraní o chiriguano (hablada por el pueblo avá-guaraní en Salta, Jujuy, Corrientes, Entre Ríos, Misiones, Santa Fe y Ciudad de Buenos Aires y Gran Buenos Aires), avá-guaraní (hablado en Salta por el pueblo chané), tapiete (hablado en Salta por el pueblo tapiete) y el mbyá (hablado por el pueblo mbyá-guaraní en la provincia de Misiones).

Según Censabella (2009), la Encuesta Complementaria de Pueblos Indígenas (ECPI 2004/2005) presenta cifras polémicas con relación al número de personas que se autorreconocen como pertenecientes al pueblo ava guaraní (418) y guaraní (2372) en la región litoral. ${ }^{3}$ La cifra genera dudas por varios motivos. En primer lugar, la existencia de diferentes (auto)denominaciones del pueblo tupí-guaraní y guaraní que reflejan sus relaciones interétnicas y la autorrepresentación del grupo. En segundo lugar, la numerosa población criolla correntina, hablante o descendiente de guaraní, que no se autorreconoce como indígena. Por último, la denominación guaraní podría también incluir población descendiente de pueblos guaraníes como los mbyás e incluso descendientes de indígenas migrantes paraguayos provenientes de los pueblos ubicados al este del río Paraguay, especialmente aquellos que viven en la provincia de Misiones.
1. El corpus reúne diversos géneros discursivos (entrevistas, artículos periodísticos y notas de opinión, legislación y proyectos de ley) articulados en torno a una problemática de investigación que busca indagar sobre los sentidos, representaciones e ideologías circulantes en torno a la oficialización del guaraní.

2. Según lo define Bein (2004, p. 41), "la política lingüística abarca el conjunto de las decisiones que se toman conscientemente con relación al uso público del lenguaje, como la de instituir una lengua o variedad como oficial, dotar de escritura una lengua ágrafa, fijar una terminología, proteger las lenguas minoritarias, establecer qué lenguas extranjeras se deben enseñar en el sistema escolar público, decidir qué habilidades lingüísticas deben adquirir los estudiantes de los distintos niveles, velar por la edición de libros para ciegos, garantizarle a alguien que no conoce la lengua oficial un intérprete en los juzgados u obligar a los locutores provinciales de radio y televisión a usar la variedad culta de la capital".

3. Región integrada por Corrientes,
Entre Ríos, Misiones y Santa Fe (Argentina). 
Según el Censo Nacional de Población, Hogares y Viviendas 2010, la provincia de Corrientes posee 992.595 habitantes, de los cuales 5129 pertenecen o descienden de algún pueblo originario, es decir, menos del 1\% de la población total $(0,51 \%)$. Además, el censo especifica que hay 7646 personas migrantes, en su mayoría paraguayos (3397 personas) y brasileños (1543 personas). Aunque no se cuenta con datos estadísticos y censos oficiales, Dietrich (citado por Cerno, 2011) estima que los hablantes de guaraní no serían más de 100.000, lo que representa aproximadamente un $10 \%$ de la población provincial. Melià (1992) afirma que el guaraní en la provincia de Corrientes sería hablado por "un 50 \% [de la población], casi exclusivamente en el campo" (p. 35).

Cerno (2011, p. 12), en consonancia con Dietrich (2002) y Rodrígues (1984-1985), sostiene que el guaraní correntino constituye uno de los dialectos del guaraní criollo, es decir, una lengua hablada por población no indígena o mestiza que "surge del proceso de interacción entre españoles e indígenas durante la colonización española en las antiguas provincias del Paraguay y Corrientes (siglos XVI-XVIII)" (p. 12). Tanto Cerno (2011) como Dietrich (2002) distinguen entre "guaraní criollo" (lengua hablada por no indígenas principalmente mestizos) y lenguas guaraníes llamadas también "étnicas" porque se mantuvieron más libres de la influencia de la colonización, como el guaraní mbyá, el guaraní kaiwáy ñandeva. Por último, Cerno (2011) identifica dos variedades del guaraní hablado en Corrientes: 1) "guaraní mezclado", que se asocia a hablantes bilingües escolarizados y a la sociedad moderna, urbana e hispanohablante; y 2) el "guaraní cerrado", usado por hablantes monolingües, escasamente escolarizados y que se asocia al mundo de la cultura rural tradicional.

El guaraní se utilizó como instrumento de dominación durante la conquista y colonización hispana del territorio, la cual se consolidó gracias a la evangelización, asimilación y relocalización de las etnias precolombinas. Posteriormente, y a medida que se transformaba la composición demográfica de la población (mestizaje), se impuso la lengua española y, en consecuencia, se institucionalizó la siguiente distribución social de funciones: el español era utilizado en la administración pública por la elite gobernante y eclesiástica; y el guaraní, empleado en el ámbito doméstico, familiar, por las clases humildes, no escolarizadas y sin posibilidades de ascenso social. Esta distribución desigual de lenguas se cristaliza en los significantes utilizados para referirse a las lenguas en conflicto. Así, en una publicación del Ministerio de Educación provincial (Ministerio de Educación de Corrientes, 2017), destinada a docentes, se menciona una breve historia del guaraní y del significado de los etnónimos utilizados para referirse a estas lenguas a fines del siglo XVI. Los grupos guaraníes empleaban los etnónimos avañe'ê, 'lenguaje humano', que alude al guaraní, en contraposición a karaiñe'é,' palabra de los señores', para designar el español. Esta contraposición también se observa en los discursos que integran el corpus, tal como lo ilustramos en el apartado 4.

\section{Aspectos teórico-metodológicos: sobre el concepto de re- presentaciones}

El concepto de representaciones proviene del campo de la psicología social (Moscovici, 1979; Jodelet, 1993). En esta línea, Denis Jodelet (1993, p. 472) define las representaciones sociales como "[i]mágenes que condensan un conjunto de significados; sistemas de referencia que nos permiten interpretar lo que nos sucede, e incluso dar un sentido a lo inesperado; categorías que sirven para clasificar las circunstancias, los fenómenos y a los individuos". Es decir, la 
representación social es un concepto útil para dar cuenta de los procesos de semiosis (producción de sentido) que los miembros de un grupo van elaborando en torno a determinados fenómenos/circunstancias de "lo real" y que perfilan su particular visión acerca de dicho fenómeno.

Desde una perspectiva sociolingüística, utilizamos este concepto para dar cuenta de aquellas verbalizaciones o prácticas (juicios de valor, evaluaciones, calificaciones, aserciones, proposiciones) que los sujetos - que comparten una comunidad-enuncian sobre las prácticas lingüísticas propias y/o ajenas, sobre el valor y significaciones asociados a lengua/s y variedad/es presente/s en una comunidad de habla y sus hablantes. Para López García (2015, p. 24), las representaciones "definen y salvaguardan la especificidad de un grupo social, son informativas y explicativas de la naturaleza de las relaciones que ocurren dentro del grupo (y entre grupos), así como del individuo en ese contexto".

Bein (2010a, s.p.) define el concepto de representación sociolingüística como:

una suerte de constructo ideológico interpuesto entre la praxis lingüística real y la conciencia social de esa praxis. Como toda ideología, la representación sociolingüística está dotada de materialidad discursiva; por ejemplo, de proposiciones como "el alemán es difícil”, "las lenguas clásicas fomentan el pensamiento lógico" o "el portugués se entiende sin estudiarlo", pero esos discursos tienen un efecto perlocutivo que varía según la situación socioeconómica de la comunidad que las enuncia y sobre la que actúan, y según su vinculación con los demás discursos circulantes en esa comunidad.

En esta investigación, la identificación de representaciones en torno al guaraní se ha basado en la búsqueda de lexemas, sintagmas y enunciados asociados al término "guaraní" dentro del corpus, es decir, nos preguntamos cuáles son los significantes asociados a dicho lexema. Esta búsqueda nos permite reconstruir una red o mapa semántico que reúne nominalizaciones o proposiciones contradictorias; por ejemplo, "guaraní" es calificado como "lengua" o "dialecto"; es definido como "medio de comunicación cotidiana de miles de correntinos" $\mathrm{y}$, a la vez, aparece asociado al sintagma de "pérdida de la utilización de la lengua autóctona". Las representaciones son polisémicas (Jodelet, 1993), de naturaleza polémica y agresiva, condensan un conjunto de significados, dado que encadenan (en el plano sintagmático) núcleos de predicación que evocan (en el plano paradigmático) creencias o idealizaciones provenientes de ideologías diversas e incluso contrapuestas. Ese tejido donde coexisten representaciones contradictorias en torno al guaraní indica o refleja los singulares modos de apropiación del objeto cognoscitivo "guaraní" por parte de distintos colectivos y actores sociales. El análisis de las representaciones sociolingüísticas pretende desentrañar cómo son esos modos de apropiación y a qué intereses y procesos históricos responden. En este caso, el análisis de las representaciones sociolingüísticas en torno al idioma guaraní pretende (des)articular los tramos discursivos que permiten construir y naturalizar una relación semántica, ideológicamente situada, capaz de asociar "guaraní" a frases como "dialecto de indios, menchos y tapes" o a "lengua madre de los correntinos". En el trabajo con los discursos sobre la lengua guaraní, la atención está puesta en estos significantes ya que estas denominaciones, como señala Glozman (2015):

condensan-y en muchos casos olvidan-disputas históricas y procesos de conquista y colonización, nombres que operan como si esas lenguas y variedades fueran objetos siempre-ya-dados, de existencia singular, concreta y natural en el mundo. Aquello 
que se materializa en esas denominaciones son, entonces, imaginarios de lenguas y variedades lingüísticas, sujetos a disputa. (pp. 17-18)

A las representaciones sociolingüísticas se les indexan valores sociales, por eso deben ser analizadas teniendo en cuenta ciertos factores que las configuran, por ejemplo: el contexto inmediato, el contexto social, la historia y las ideologías de la comunidad. Es decir, para comprender el sentido de una proposición como el "guaraní es, a los correntinos, nuestra lengua materna", resulta necesario analizar las condiciones de producción de este discurso: quién lo enuncia, con qué intencionalidad/es, en qué contexto sociopolítico e histórico local, regional, nacional e internacional y qué tipo de efecto performativo busca conseguir. En última instancia, el fin de estudiar las representaciones hegemónicas circulantes en una comunidad permitiría conocer y explicar la génesis de ciertas actitudes y comportamientos lingüísticos y, a la vez, modificarlos mediante contradiscursos (Bein, 2010a).

\section{Análisis de las representaciones en torno al guaraní}

\subsection{La Ley 5598/2004}

En el año 2000, un grupo de escritores correntinos solicita a las autoridades provinciales la protección y promoción de la lengua guaraní. En 2002, el diputado justicialista Walter Insaurralde presentó a la Cámara de Diputados de la provincia de Corrientes el proyecto de ley denominado: "Declaración del Guaraní como lengua oficial de la provincia de Corrientes junto al castellano" (El Litoral, 11 de octubre de 2004). El 28 de septiembre de 2004 se sanciona la Ley $\mathrm{N}^{\circ} 5598$, cuyos artículos contemplan:

Artículo 1․-ESTABLÉCESE el guaraní como idioma oficial alternativo de la Provincia de Corrientes.-

Artículo $2^{\circ}$-:- INCORPÓRASE en todos los niveles del sistema educativo provincial la enseñanza del guaraní.-

Artículo $3^{\circ}$.- FOMÉNTESE, consérvese, presérvese y difúndase la literatura en guaraní.-

Artículo $4^{\circ}$-- CRÉASE un órgano permanente de rescate y revalorización de la cultura guaraní en el área correspondiente.-

Artículo $5^{\circ}$ - IMPÓNESE la señalización topográfica y otra índole en ambas lenguas.Artículo 6 -. PROMUÉVASE la irradiación de audiciones a través de las cuales se enseñe y practique la lengua guaraní.-

Los titulares de la prensa local anunciaban así la noticia: “El guaraní es la segunda lengua oficial en Corrientes" (El Litoral, 30 de septiembre de 2004); "Por Ley, el Guaraní es la lengua oficial provincial" (sic) (El Litoral, 29 de septiembre de 2004), "Ya somos bilingüe" (sic) (Época, 9 de octubre de 2004). Los artículos correspondientes a estos titulares no explican qué significa o cuáles son las implicancias de otorgar al guaraní el estatus de lengua oficial; incluso propician confusiones o malentendidos ya que no se lo declara "la" lengua oficial de Corrientes, sino lengua oficial alternativa. En palabras de algunos funcionarios públicos entrevistados, lengua oficial alternativa significaría "equipararlo al español" (1a) y que no es obligatorio (hablarla) (1b):

1a.Bueno, la verdad que estamos muy satisfechos por eh...el impacto, la receptividad y por el nivel de conciencia que se ha alcanzado este...en la necesidad de la 
implementación del guaraní. En los dos aspectos, tanto en el punto de conquista cultural porque la Ley equiparó al español como idioma oficial alternativo en la provincia. (Entrevista. M. funcionario público, septiembre de 2006)

1b. se presenta el hecho del guaraní como idioma alternativo. Mucha gente cree que es una imposición [...] No estamos hablando de que todo el mundo tiene que hablar guaraní, estamos hablando de "alternativo", que no necesariamente quiere decir obligatorio. (Entrevista. CT, titular de la Comisión de Políticas lingüísticas, septiembre de 2006).

En síntesis, esta ley se manifiesta como un reconocimiento simbólico y una acción para jerarquizar el estatus de la lengua, ya que busca reivindicar y promover su uso en distintos ámbitos públicos (administración, escuela, cartelería, radiodifusión y literatura).

En el año 2012 surge la Ley $\mathrm{N}^{\circ}$ 6176, que conmemora el 28 de septiembre como día provincial de la lengua guaraní, con el fin de promover acciones de revitalización y visibilización del idioma. Aunque la Ley 5598 todavía no ha sido reglamentada, 4 estas normativas marcan un giro en relación con las políticas lingüísticas previas.

\subsection{Contextualización histórica}

En el siglo XVIII, el gobernador de Buenos Aires, Francisco de Paula Bucarelli y Úrsula, ejecutó la expulsión de los jesuitas y emitió algunas ordenanzas. En una de ellas estableció la enseñanza del castellano en el territorio del Virreinato del Río de la Plata y prohibió el uso del guaraní en las escuelas:

Para conseguir civilizar perfectamente a estas gentes [...] es la base fundamental el introducir en estos pueblos el uso de nuestro propio idioma. [...] Habrá en todos los pueblos una escuela para la educación de los niños pequeños [...]: en ellas se les ha de enseñar la doctrina cristiana, a leer, escribir y contar en nuestro idioma [...] y no se permitirá que los muchachos hablen la lengua guaraní durante el tiempo que asistan a sus distribuciones (Instrucción del 23 de agosto de 1768; cit. en Gandulfo, Miranda, Rodríguez y Soto, 2015).

Después de la emancipación del Virreinato del Río de la Plata, la primera provincia en sancionar una ley de educación provincial fue Corrientes, cuyo gobernador, Juan Gregorio Pujol, en 1853, promulga la Ley de Educación Primaria de la provincia de Corrientes. Allí se establecen los contenidos mínimos y se hace mención al "idioma patrio" como modo de aludir al castellano y negar la presencia de otras lenguas en la provincia correntina (Gandulfo, Miranda, Rodríguez y Soto, 2015).

La política lingüística y educativa de homogeneización cultural o sumersión (López, 2013), cuyo objetivo será el reemplazo de las lenguas indígenas por el castellano, continúa vigente hasta mediados del siglo XX.

En 1884 se sanciona a nivel nacional la Ley de Educación Común $\mathrm{N}^{\circ}$ 1420, que establece la educación primaria, obligatoria y gratuita, que menciona un "mínimum" de instrucción obligatoria en asignaturas como "lectura y escritura; aritmética [...], Geografía particular de la República y nociones de la geografía universal, historia particular de la República y nociones de historia general, idioma nacional [...]" (art $\left.\mathrm{N}^{\circ} 6\right)$. Bein (2010b) señala que esta ley hace referencia a la lengua oficial utilizando frases como "idioma nacional", en referencia
4. Se presentaron al Poder Ejecutivo de la provincia de Corrientes solicitudes en las cuales se pide por la pronta reglamentación de esta ley, como por ejemplo, la resolución presentada por el senador Rubén Pruyas (Partido Justicialista) y el Expediente $N^{\circ}$ 9046/14 emitido por la diputada Sonia López (Partido Comunista). 
al español, pero sin especificar de qué lengua se trata. Durante la década del ochenta se implementaron políticas de castellanización y homogeneización, a través de estrategias lingüísticas -como el uso del sintagma "idioma nacional"destinadas a invisibilizar la diversidad de las lenguas indígenas de nuestro territorio, consideradas como portadoras de "la barbarie", y de las lenguas de inmigración.

En 1951, Corrientes sanciona la Ley N 1576, que establece la educación primaria elemental, obligatoria y gratuita para los niños a partir de los seis años y hasta los dieciocho. En ella se establece que

[e]l mínimo de educación obligatoria corresponde al conocimiento de las siguientes materias: Lenguaje (lectura y escritura). Matemáticas (Aritmética elemental). Civismo y moral. Conocimientos básicos de Historia, Geografía, Agricultura y Ganadería, Ciencias Naturales, Nociones de Higiene y Puericultura, Economía Doméstica, Previsión y Ahorro, Educación Física, Trabajo Manual y Folklore Nacional y Regional. Conocimientos de las Constituciones Nacional y Provincial, haciendo resaltar las conquistas sociales recientemente consagradas. Nociones básicas de la religión Católica Apostólica Romana (art. $N^{\circ} 8$ ).

En 1994, Corrientes adhiere a los lineamientos de la Ley Federal de Educación 24195/1993 a través de la Ley provincial №4866, y hasta el año 2018 estuvo regulada por la Ley de Educación Nacional N²6206/2006. Recién a fines de ese año se sancionó la Ley de Educación de la provincia de Corrientes $\mathrm{N}^{\circ}$ $6475 / 18$, que contempla, por primera, vez la enseñanza del guaraní en tres niveles educativos (inicial, primario y medio) en el marco de la Educación Intercultural Bilingüe dentro del ámbito provincial.

Esta breve reseña de las políticas lingüísticas previas permite observar la vigencia de un discurso hegemónico que pretendía invisibilizar y estigmatizar las lenguas indígenas y de inmigración. En contraposición, el proyecto de rescate del guaraní marca un giro en las políticas implementadas en el ámbito provincial, cambio favorecido por el contexto nacional e internacional.

La ley 5598/2004 de oficialización del guaraní surge en un contexto políticosocial basado en políticas de respeto a la diversidad, de reivindicación y reconocimiento de derechos jurídicos a las poblaciones indígenas (Briones, 2005, p. 32). Este tipo de política se manifestó, por ejemplo, en reformas constitucionales de diferentes países de América Latina; específicamente, en Argentina, en la reforma constitucional del 1994, cuyo artículo $\mathrm{N}^{\circ} 75$, inciso 17 , reconoce la preexistencia étnica de las poblaciones indígenas en el territorio nacional y garantiza: "el respeto a su identidad y el derecho a una Educación Bilingüe e Intercultural $[. . .]^{\prime \prime}$. Otros documentos internacionales afines a esta política, y a los que Argentina adhirió, son: la Declaración Universal de los Derechos Lingüísticos, en 1997; la incorporación de la modalidad Educativa Intercultural Bilingüe (EIB) a la currícula oficial de la mayoría de los países latinoamericanos; es decir, se reconoce la EIB como "derecho étnico y colectivo" y como programa educativo para indígenas (Walsh, 2010, p. 81).Incluso, la creación del Mercado Común del Sur (MERCOSUR) en 1991 integrado por Argentina, Brasil, Uruguay y Paraguay, también se hace eco de esta ideología lingüística. En distintos documentos se afirma que las lenguas oficiales del MERCOSUR son el español y el portugués, y que, para la redacción y comunicación de los documentos oficiales, se utilizará el idioma del país sede de cada reunión (art $\mathrm{N}^{\circ} 46$ del Protocolo adicional al Tratado de Asunción sobre la estructura institucional del MERCOSUR, Protocolo de Ouro Preto). 
Estos lineamientos internacionales que promueven la integración regional sin desconocer las minorías étnicas fueron y son considerados en las políticas lingüístico-educativas de Argentina desde fines del siglo XX. La Ley Federal de Educación $\mathrm{N}^{\circ}$ 24.195/1993, en su artículo $\mathrm{N}^{\circ}$ 5, inciso 19, establece: “El derecho de las comunidades aborígenes a preservar sus pautas culturales y al aprendizaje y enseñanza de su lengua" a partir de la implementación de programas especiales de "rescate y fortalecimiento de las lenguas y culturas indígenas, enfatizando su carácter de instrumento de integración" (Bein, 2010b, p.312). A diferencia de la anterior, la Ley de Educación Nacional $N^{\circ} 26.206 / 2006$ no solo incorporará la Modalidad Educativa Intercultural Bilingüe como una de las nueve modalidades del sistema educativo nacional, sino que también priorizará la integración latinoamericana e incorporará contenidos curriculares comunes a los países del MERCOSUR, 5 tal como lo expresa el artículo $\mathrm{N}^{\circ} 92$ de la Ley $N^{\circ} 26.206 / 2006$ : "el fortalecimiento de las perspectiva regional latinoamericana, particularmente de la región del MERCOSUR, en el marco de la construcción de una identidad nacional abierta, respetuosa de la diversidad" (Bein, 2010b, pp. 320-321).

\subsection{Análisis de las representaciones en torno al guaraní}

Durante las semanas previas a la sanción de la ley, y diez días después -previos a la promulgación- la prensa gráfica y los portales locales de noticias se convirtieron en importantes órganos de difusión del proyecto legislativo y de manifestación de adhesiones de distintos colectivos sociales (académicos, miembros de la Central de Trabajadores de la Argentina (CTA) filial Corrientes, escritores, poetas, músicos, entre otros). Las notas de opinión, los artículos y las notas de adhesión reproducen numerosas representaciones sobre el guaraní que aluden a "lengua o idioma", "dialecto", "mezcla", "patrimonio o herencia", etc. A fines expositivos, analizamos las representaciones más recurrentes reagrupándolas en tres ejes principales: (a) estatus lingüístico, (b) identidad $\mathrm{y}$, por último, (c) la relación lengua-escuela.

En los discursos analizados prevalece la estrategia argumentativa de encadenar y contrastar representaciones o imágenes estigmatizantes en torno al guaraní, asociadas al pasado, con nuevas representaciones que buscan legitimar el proyecto de oficialización del guaraní. Esta oposición de bloques de representaciones se puede visualizar contrastando los gráficos 1 y 2 .
5. El 7 de diciembre de 1995, Argentina, Brasil, Paraguay y Uruguay firman el "Programa de Acción del Mercosur”, que establece, en relación con la educación: "El objetivo permanente en esta área deberá ser la mejora de la calidad de la educación en los Estados Partes, incorporándole una dimensión cultural y lingüística. Asimismo se deberá profundizar la integración educativa. A tales efectos se deberán compatibilizar los distintos niveles educativos, establecer instancias de formación conjunta de recursos humanos, establecer planes de enseñanza aprendizaje de los idiomas oficiales del Mercosur, articular los sistemas de información nacionales y reconocer la formación académica. A tales efectos se deberán compatibilizar los distintos niveles educativos, establecer instancias de formación conjunta de recursos humanos, establecer planes de enseñanza - aprendizaje de los idiomas oficiales del Mercosur, articular los sistemas de información nacionales y reconocer la formación académica"(Decisión Nº 9, Capítulo II, subtítulo 3.5). 
Gráfico 1: Representaciones en torno al guaraní antes de su oficialización.

Gráfico 2: Representaciones en torno al guaraní después de su oficialización.
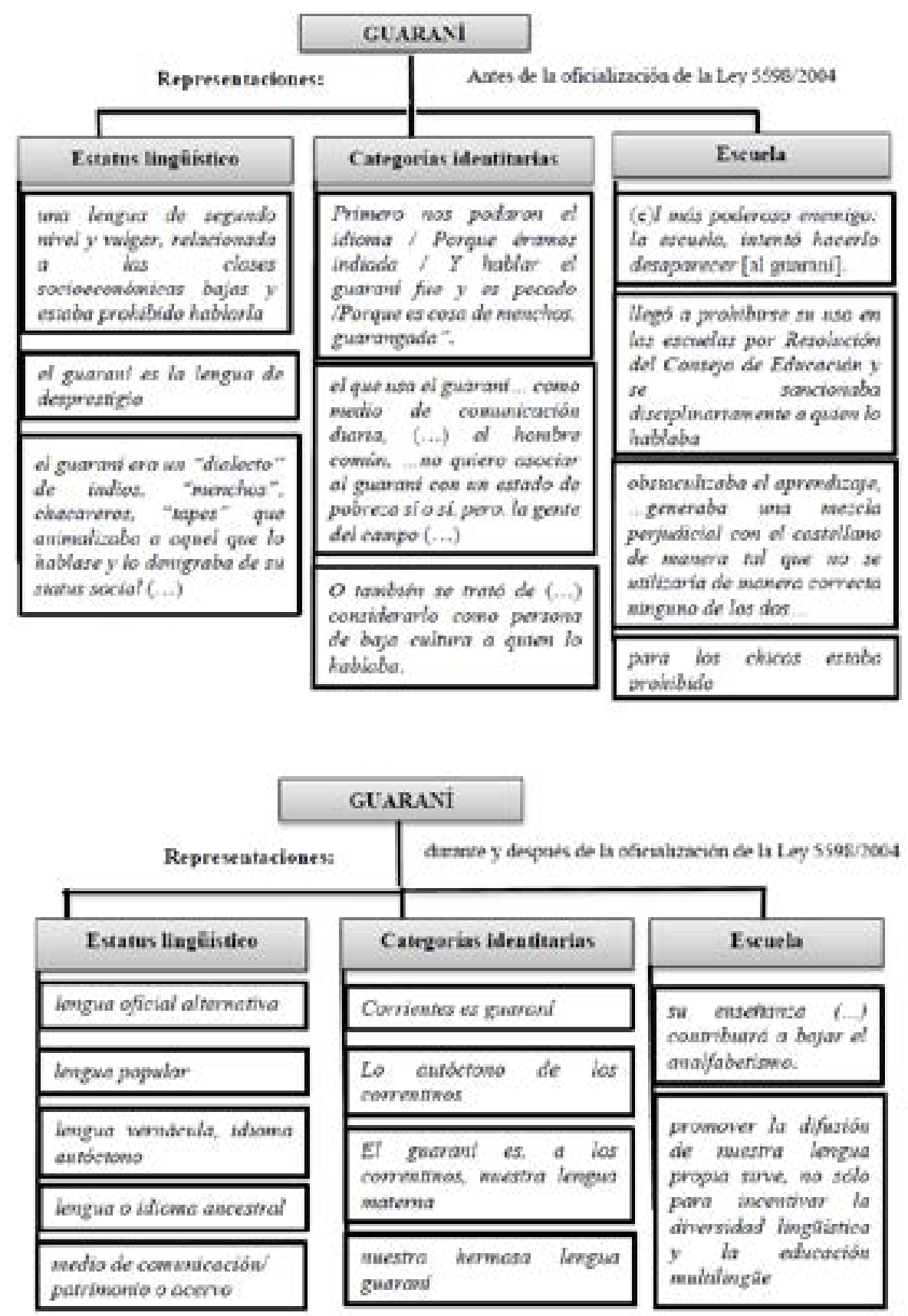

4.2.1. Representaciones sobre el estatus lingüístico del guaraní "hoy en día ya es idioma"

En los discursos periodísticos identificamos que el lexema "guaraní" funciona como un adjetivo, modificador de un núcleo nominal, que con mayor frecuencia es el sustantivo "lengua" o "idioma" (2) o funciona como núcleo nominal y se acompaña de un modificador indirecto o una predicación (3), que define o caracteriza la lengua.

2. Este es el sentido más profundo que comparten las normas vigentes al respecto, la Ley $N^{\circ} 5598$ (2004) que establece la lengua Guaraní como idioma oficial alternativo de la Provincia; incorpora en los niveles del sistema educativo la enseñanza del idioma Guaraní e implanta el fomento, la conservación y la difusión de la literatura en 
dicho idioma, asimismo crea un Organismo Permanente de rescate y revalorización. Por su parte, y más recientemente (2012), la Ley № 6176, que instituye el día 28 de septiembre de cada año como "Día Provincial de la Lengua Guaraní", estableciendo que se arbitren los medios para divulgar, incentivar y difundir en todo el territorio provincial, diferentes expresiones culturales referidas a la Lengua Guaraní. (Actualidadesquina.com, 26 de septiembre de 2014)

3a. Las leyes son la 5.598, que establece el guaraní como idioma oficial alternativo de la Provincia, incorporando en los niveles del sistema educativo la enseñanza de dicho idioma. (Noticias de la Cruz, 1 de marzo de 2015)

3b. El guaraní es, a los correntinos, nuestra lengua materna y como tal quizás sea el instrumento de mayor alcance para la preservación y el desarrollo de nuestro patrimonio cultural tangible e intangible. (Actualidadesquina.com, 26 de septiembre de 2014)

En ambos casos, esta nueva asociación sintagmática se opone a representaciones y discursos anteriores en los que el guaraní se representaba como "lengua de segunda, vulgar" (4a), un "dialecto de indios, menchos, tapes" (4b).

4a. "Durante mucho tiempo el guaraní fue considerado una lengua de segundo nivel y vulgar, relacionada a las clases socioeconómicas bajas y estaba prohibido hablarla, lo que generó que se vaya perdiendo su uso por vergüenza o desprecio", explicó el estudioso de la lengua guaraní Aurelio Schinini. (El Litoral, 8 de mayo de 2010)

4b. [...] el guaraní era un "dialecto" de indios, "menchos", chacareros, "tapes" que animalizaba a aquel que lo hablase y lo denigraba de su status social, así ya lo reflejaban y resumían los versos del Pai Zini: "Primero nos podaron el idioma / Porque éramos indiada / Y hablar el guaraní fue y es pecado /Porque es cosa de menchos, guarangada. (Actualidadesquina.com, 26 de septiembre de 2014)

4c. Orgulloso Liuzzi asegura hablar guaraní [...] Yo siempre digo que en Corrientes, el castellano se convirtió en la lengua de "prestigio" y el guaraní es la lengua de "desprestigio". (El Litoral, 11 de octubre de 2004)

Además de caracterizar el estatus lingüístico, en (4b) se mencionan "categorías" que aluden a un otro estigmatizado por su condición humilde, la precariedad laboral, su ignorancia o su mal desempeño en el uso del español, términos utilizados para insultar. Entre estas categorías, destaca la de "mencho", término que alude al peón rural correntino, a quien se le paga por mes. Poenitz (2012, p. 14) señala que

[e]n el mencho correntino [...] tipo social característico de ese espacio rural, se sintetiza esa simbiosis cultural guaraní-misionera y correntina. Heredero y portador de la "avaidad" guaraní, dueño de la lengua guaraní de sus antepasados, el mencho conjuga esa sangre guaraní con la del conquistador hispano.

Es decir, el mencho correntino, como el gaucho en Rio Grande do Sul o el paisano en Paraguay, resulta del mestizaje del criollo y el guaraní que se produce a partir de la dispersión de los guaraníes tras la expulsión de los misioneros jesuitas y la migración a las estancias de los latifundistas criollos de la Banda Oriental, Entre Ríos, Corrientes y Paraguay. Por otra parte, el término tape o tapé es un vocablo guaraní que significa "camino"; además, es un etnónimo (tapé 'persona') para referirse a un grupo de guaraníes que habitó en las misiones jesuíticas 
orientales entre los ríos Paraná y Uruguay hasta las primeras décadas del siglo XIX, y el topónimo de dicha región (Maeder y Gutiérrez, 1994).

El sintagma "lengua oficial alternativa de la provincia de Corrientes" genera un efecto de ruptura, reformulación y cuestionamiento de aquellas representaciones estigmatizantes (4), afines a una política lingüística previa, cuyo objetivo central era la sustitución de las lenguas autóctonas y la castellanización. En las palabras de los hablantes y no hablantes de guaraní encuestados se puede apreciar una actitud vacilante y la redefinición del estatus del guaraní, tal como se observa en las siguientes interacciones (5) y (6).

5. R: Hablaban guaraní nomás ellos, los bisabuelos y los abuelos hablaban guaraníno más, pero también hablaban en el idioma, este español que dicen ustedes, nuestro idioma hablaban, pero casi los abuelos hablaban en guaraní, nomás y cuando habían criatura todo hablaban en guaraní nomás...los mayores, todo era en guaraní, así cuando estábamos jugando, así, todo hablaban en guaraní, así es...

L: ¡No es un idioma, es un dialecto nuestro! Pero ahora va a entrar como idioma...

R: ¡Cómo no va a ser un idioma Loli, si con eso nacimos!

L: Bueno, a nosotros en la escuela nos enseñaban que era un dialecto y ahora escuché, hace poco, porque ahí, en la televisión de dirección de Cultura, acá de Corrientes, dijo que va a ser un idioma...así que...

R: Para mí, para mí es un idioma, porque otro idioma no había, nuestro antepasado, no había otro idioma, ¡Era guaraní! (Roberto, jubilado y hablante de guaraní, y Loli, no hablante. 25 de noviembre de 2006)

6. A: El idioma guaraní, o sea dialecto, hoy en día ya es idioma eso es lo que trató la ley ¿no? y me parece muy bien que enseñen a nuestros hijos, nuestras raíces, porque nosotros no conocemos nuestro pasado, no sabemos. (Alberto, excombatiente de Malvinas y hablante de guaraní, 30 de noviembre de 2006)

Prevalece en el corpus analizado la construcción del lexema guaraní conformando frases como "idioma guaraní" o "lengua guaraní". El uso del término lengua o idioma como sinónimo o equivalente a guaraní es una de las estrategias discursivas que permiten jerarquizar este idioma, destacar "su estatus", en oposición a la representación social vigente que lo calificaba como "dialecto". Algunas variantes de aquellas frases son: lengua ancestral (Noticias de la Cruz, 1 de marzo de 2015), lengua popular (Época, 9 de octubre de 2004), lengua materna (Actualidadesquina.com, 26 de septiembre de 2014), lengua vernácula, lengua autóctona, lengua madre, entre otras.

Otra estrategia discursiva recurrente para generar la adhesión de la opinión pública en torno a la reivindicación del guaraní es remitir a un origen común, autóctono, asociarlo a un pasado ancestral que sobrevivió a la violencia de la conquista y colonización española (7). Estas representaciones se articulan, desde un relato cuasi épico, con las verbalizaciones en torno al "ser correntino" o a "la estirpe correntina que se formó de la mixtura entre lo guaraní y lo criollo" (Epígrafe, El Litoral, 17 de julio de 2006).

7a. Al referirme al guaraní, lo hago a lo cultural y a lo lingüístico de la cuestión. A lo que existe subyacente en nuestra sociedad. Aquello que quedó después del proceso de conquista y extermino del aborigen que pobló por cientos de años 
estas tierras, que vio llegar a los españoles, en 1528 en forma amistosa, pero a parir [sic] de 1588, fundación de San Juan de Vera de las Siete Corrientes, en que los españoles se reparten tierras y aborígenes en encomiendas, inicia un permanente estado de guerra, caciques como Canindeyú, Payaguán, Aguará, Coembá y Mboripé reaccionan violentamente [...] Pero en algún lugar de su geografía, o sobre sus ruinas de antiguos pueblos destruidos, sobrevivió la memoria. A partir de la música, de un cántico religioso, de una leyenda arraigada o de la misma sangre mezcla de criollo con guaraní que corre en las venas del correntino hoy [...] Eran sectores de origen mestizo en cuyos hogares, como hoy en día se adviene al mundo en idioma Guaraní. La resistencia y su consecuente permanencia radica en el corazón del hogar, alentado por el alma recatada y paciente de la mujer guaraní, transmitida de generación en generación. (nota de W. Insaurralde, El Litoral, 17 de julio de 2006)

7b. La imposición de la lengua de los vencedores tras la colonización de estas tierras fue para Liuzzi [...] "una castración de la cultura" de los correntinos, "guaraní hablantes traumatizados por la cultura dominante", como los define. [...] la promulgación de la ley sancionada por la Legislatura correntina "abre expectativas de liberación", porque asegura que permitirá a los correntinos "hablar su propia lengua sin pedir permiso. (El Litoral, 11 de octubre de 2004)

\subsubsection{Representaciones del guaraní como categoría identitaria: “Corrientes es guarani"}

La asociación entre guaraní y lengua en general se acompaña de construcciones genitivas o de marcadores posesivos que refuerzan la configuración de un referente común: el ser correntino, la correntinidad (8). Abonan esta construcción identitaria la presencia de la primera persona del plural (nuestra, nosotros), la suma de adjetivos y expresiones calificativas subjetivas que asocian el uso de la lengua con valores positivos y muy estimados por los correntinos, como: lo bello, lo sencillo, lo ingenioso, la vida, la naturaleza, las tradiciones y la cultura, la familia, el trabajo, la religiosidad, el chamamé, las artes, etcétera.

8a."El guaraní es, a los correntinos, nuestra lengua materna y como tal quizás sea el instrumento de mayor alcance para la preservación y el desarrollo de nuestro patrimonio cultural tangible e intangible. Es por ello que toda iniciativa que intenta promover la difusión de nuestra lengua propia sirve, no sólo para incentivar la diversidad lingüística y la educación multilingüe, sino también para crear mayor conciencia sobre las tradiciones lingüísticas y culturales de nuestra historia y raíces culturales e inspirar a la solidaridad basada en el entendimiento, la tolerancia y el diálogo”, explica el proyecto del senador Pruyas. [...] “A cuántos de nosotros se nos negó aprender nuestra hermosa lengua guaraní bajo los falaces argumentos de que obstaculizaba el aprendizaje, que generaba una mezcla perjudicial con el castellano de manera tal que no se utilizaría de manera correcta ninguno de los dos [...] Hoy, se nos plantea la oportunidad de reparar históricamente las injusticias y asimetrías que aún coexisten, y dar lugar a la voluntad de acrecentar y sostener la diversidad cultural de la que somos parte; éste es el tiempo de revalorizar nuestro legado, hoy nos dimos cuenta y desde todos los ámbitos, que el guaraní nos enriquece, su cultura nos lleva a la maravillosa dimensión de lo simple, de lo sencillo, ese soplo espiritual profundo que se asienta en lo más recóndito de nuestro ser y nos permite ser auténticos. Muy lejos de "entorpecernos", el guaraní nos abre horizontes y nos otorga perspectivas, nos recuerda lo verdaderamente valioso de la vida, nos acerca simbióticamente a la naturaleza y fraternalmente a nuestro prójimo. (Actualidadesquina.com, 26 de septiembre de 2014) 
8b. Después de más de 500 años de intento de hacerlo desaparecer, el idioma guaraní demostró su vitalidad espiritual manteniéndose vivo como lengua popular, como medio de comunicación cotidiana nutriendo, a la vez, otras manifestaciones culturales: la música, las letras, las artes plásticas, etc., del pueblo correntino [...] En síntesis: amemos con pasión, dignidad y altivez esta riquísima lengua nuestra: el guaraní. (Época, 9 de octubre de 2004)

Es decir, se legitima el proyecto guaraní configurándolo como símbolo o diacrítico identitario, parte constitutiva de la identidad correntina, que se expresa en la proposición "Corrientes es guaraní", reiterada en los discursos de los ciudadanos encuestados (9). El guaraní se convierte en símbolo de la identidad correntina; hablar la lengua guaraní es un valor, tanto como el patriotismo, el chamamé o la religiosidad.

9a. R: Me parece que es así, totalmente de acuerdo [...] realmente me parece que (el guaraní) nos identifica, digamos, no sé, para mí Corrientes es guaraní, identifica a Corrientes.

F: Aparte, resalta la figura correntina, no es nada denigrante, digamos, como alguno capaz le quieren hacer (Rosa, 47 años, y Federico, 18 años. 12 de septiembre de 2006).

9b. M: ¿Qué valoración tiene para usted el guaraní, el guaraní para el correntino?

A: Para mí es lo que nos identifica, a mi mandame a cualquier lugar de Corrientes, pero mandame al Chaco y ya no me gusta, porque ya no saben hablar en guaraní. (Alberto, excombatiente de Malvinas y hablante de guaraní, 30 de noviembre de 2006)

Como veíamos en (4b) y en (7), las representaciones en torno al guaraní expresan referencias, calificaciones o valoraciones acerca de quiénes y en qué circunstancias utilizan esta lengua (10) y (11).

10. A: Acá, acá pasan dos cosas absolutamente raras, eh, raras o no raras, tiene su razón de ser obviamente, que hay que leer en nuestra historia, que [...] claro porque cambiar, cómo cambiar en la gente en el... porque el que lo usa, el que usa el guaraní como lengua, como, como medio de comunicación diaria, el hombre, digamos el hombre común, el que es decir, no hay que, no quiero asociar al guaraní con un estado de pobreza sí o sí, pero, la gente del campo que ya por naturaleza tenemos un perfil bajo, baja autoestima por un montón de cosas, por condiciones de vida, por la lengua que manejas [...] eh no, yo creo que sí, que para esa gente, por lo menos sigue de alguna manera no vedada, restringido el uso a su ámbito a su ámbito familiar o de confianza [...]. (Andrés, docente y hablante de guaraní, 11 de noviembre de 2006)

Si bien, la lengua ha sido asociada a hablantes de clase humilde, los hablantes reflexionan acerca del uso de la lengua como estrategia empleada por caudillos y líderes políticos o sociales para conseguir adhesión (11).

11. Corrientes es una provincia feudal, el señor feudal te habla guaraní a boca de jarro, en el lugar en donde esté, el mismísimo gobernador, el anterior Colombi, no tenía reparos, reparos en un sentido no, en hablar guaraní, en, en la reunión en donde esté por el interior [...] el señor feudal lo usa de esa manera...como algo exótico ¡Uy!... es como un elemento de ornato para su lengua, esa gente no tiene ningún reparo, supongo que no tienen el menor respeto por la lengua tampoco. (Andrés, docente y hablante de guaraní, 11/11/2006) 
Por último, conviene señalar que la conformación de un nosotros constituyó una estrategia eficiente para cohesionar la opinión pública en favor del proyecto guaraní y también para oponerse y confrontar con adversarios políticos y funcionarios (el gobernador Ricardo Colombi, el senador titular de la Comisión Educación y Cultura del Senado y el ministro de Educación, Carlos Vignolo, afines a la UCR), tal como se observa en artículos de la prensa durante la semana previa a la sanción (12a) y previa a la promulgación de la ley por parte del Ejecutivo (12b).

12a. El senador provincial por el radicalismo [Sergio Flintas, titular de la Comisión de Educación y Cultura], que además es cordobés, insistió además que el proyecto es "inaplicable" [...] "Como el senador no es de acá, no alcanza a comprender lo importante que es esto para los correntinos", señaló Insaurralde haciendo referencia a la procedencia cordobesa del legislador provincial. (El Litoral, 12 de septiembre de 2004)

12b. Temen que el gobernador se tome revancha del legislador que votó en contra de la reeleccióny vete la propuesta [...] Así, una disputa de tinte político podría echar por tierra este proyecto de ley que después de 400 años, permitiría que en suelo guaraní se vuelva a hablar la lengua vernácula, ya que algunos entenderían un posible veto del gobernador Ricardo Colombi, como una especie de revancha contra el legislador sanroqueño que no acompañó con su voto la movida recepcionista del gobierno... Sin embargo y de acuerdo a las manifestaciones del ministro de educación de la provincia, Carlos Vignolo, el diputado peronista prevé un rechazo a su propuesta por parte del gobierno que tiempo atrás encontró en él un obstáculo para el avance con la intentona reeleccionista. (El Litoral, 11 de octubre de 2004)

\subsubsection{Representaciones sobre la lengua en la escuela: de enemigo a instru- mento de inclusión}

Como mencionamos en el apartado 4.1, desde el siglo XVIII y hasta fines del siglo XX se implementaron diversas políticas lingüísticas que han respondido a un objetivo común: la sustitución de las lenguas autóctonas y/o de inmigración en favor del castellano, considerado alternativamente como "lengua de prestigio", la "lengua de los señores", "idioma patrio". En el marco de estas políticas lingüístico-educativas y, en relación con la lengua guaraní, la escuela tuvo el rol de sancionar, castigar su uso en dicho ámbito; después de la oficialización del guaraní se pretende transformar esas representaciones sobre la relación lengua (guaraní)-escuela.

La escuela tiene inicialmente una valoración negativa porque durante mucho tiempo fue una institución donde estaba prohibido hablar la lengua, tal como lo señalan distintos actores sociales: académicos (13a), funcionarios públicos (13b) y hablantes de guaraní encuestados (13c).

13a. En épocas pasadas, llegó a prohibirse su uso en las escuelas por Resolución del Consejo de Educación y se sancionaba disciplinariamente a quien lo hablaba. $\mathrm{O}$ también se trató de ridiculizar, de subalternizar, de considerarlo como persona de baja cultura a quien lo hablaba por ser idioma de los indios, o más despectivamente de los "menchos". En una palabra, se trató de provocar un complejo de inferioridad a los que se expresaban en esta lengua. (Época,9 de octubre de 2004).

13b. En el norte, en el sur, en el este y oeste, el Guaraní se manifiesta a pesar de haber tenido, durante 300 años, al más poderoso enemigo: la escuela, intentó 
13c. Sí, eh papá habla maso, maso, entiende obviamente, todo, por ahí le cuesta llevar una conversación...fluida en guaraní, la que habla mejor es mamá.. entonces, eh... para los chicos estaba prohibido, nosotros teníamos que salir afuera, o... o no estar cerca de la gente que hablaba... y... pero, iera imposible! porque los chicos que nos rodeaban a nosotros, cuando nosotros jugábamos, que compartíamos 30 $\mathrm{Km}$. de camino a la escuela a caballo, era únicamente guaraní... ¡No podías hablar en castellano!, era imposible, si te miraban mal, dicen que papá y mamá, cuando se casaron, cuando llegaron a esa zona con un par de hijos ya, eh toda la gente hablaba guaraní, únicamente guaraní, eso sí era mucho más fuerte la presencia del guaraní, habrá sido no sé, en la década del cincuenta, sí.. entonces decían cuando los escuchaban hablar, decían porque en mi casa hablaban en castellano y entonces decían éstos son 'angaú' de categoría...eh social, digamos, porque manejaban el y ese era el imaginario que había, que mientras vos manejes el castellano, vos tenías cierta categoría... eh, social, digamos.......] durante años se condene el... a la lengua... eh para los maestros, ya te digo que a mí me pegaron la boca con cinta, y me llamó, nos sentábamos al fondo del salón parloteando en guaraní con los chicos, creo que yo me caí y puteé ien guaraní!, obviamente, ¿en qué puedo putear? Y me llamó y en silencio sin mediar palabra, tak, tak, tak, me quedé sin recreo, todo el tiempo con cinta. (Andrés, docente y hablante de guaraní, 11 de noviembre de 2006)

Estos discursos manifiestan representaciones de la escuela como un enemigo, un lugar donde estaba prohibido el uso del guaraní, considerado idioma de indios y menchos. Es decir, se infiere el rol de la institución educativa como un órgano de regulación de la distribución funcional de las lenguas y de sanción del uso del guaraní en ámbitos públicos como la escuela, el aula, el patio del recreo. En este sentido, Gandulfo et al. (2015, pp. 31-32) plantean que la prohibición del guaraní es una ideología lingüística compartida tanto por los hablantes del guaraní como por quienes no lo son; está centralmente dirigida a los niños y expresa un conflicto lingüístico que resulta en que el guaraní se hable, tratando a la vez de ocultarlo, o se considere en general que no se habla o se habla poco.

A partir de la Ley $\mathrm{N}^{\circ} 5598$, se espera convertir a la escuela en un instrumento de defensa y revalorización de la diversidad cultural y la educación multilingüe (14) y en una herramienta pedagógica para disminuir el analfabetismo.

14a. El diputado justicialista Walter Insaurralde fue uno de los impulsores del proyecto de ley para convertir al Guaraní en lengua oficial de la provincia. Dice que su enseñanza en las escuelas contribuirá a bajar el analfabetismo. (Epígrafe, El Litoral, 30 de septiembre de 2004)

14b. "toda iniciativa que intenta promover la difusión de nuestra lengua propia sirve, no sólo para incentivar la diversidad lingüística y la educación multilingüe, sino también para crear mayor conciencia sobre las tradiciones lingüísticas y culturales de nuestra historia y raíces culturales e inspirar a la solidaridad basada en el entendimiento, la tolerancia y el diálogo", explica el proyecto del senador Pruyas. (Actualidadesquina.com, 26 de septiembre de 2014)

También aquí se observa la estrategia discursiva de oponer representaciones contrarias en torno a un mismo referente conceptual que, en este caso, es la relación lengua (guaraní)- escuela. Esta oposición logra la transformación de representaciones negativas en favor de una representación positiva, superadora, que busca la adhesión de la opinión pública en torno a la implementación 
del guaraní en el sistema educativo y, en especial, la resignificación del rol de la institución en relación con la promoción de la legua autóctona.

La relación lengua (guaranî)-escuela genera un entramado de representaciones heterogéneas en torno a distintas problemáticas, como por ejemplo: bilingüismo, variedades del guaraní, estandarización, formación docente, entre otras, cuyo análisis excede el alcance de este artículo.

\section{Conclusión}

El objetivo de este artículo ha sido analizar representaciones en torno al guaraní, manifiestas en distintos discursos públicos enunciados entre 2004 y 2017.

Durante este período de tiempo se ha podido observar, en el corpus analizado, cómo se (re)producen imágenes y representaciones heterogéneas sobre el guaraní, las cuales han sido organizadas en tres ejes principales: a) sobre el estatus lingüístico, b) sobre categorías identitarias, y c) sobre el guaraní en la escuela. En cada uno de estos ejes, observamos una estrategia discursiva recurrente que consiste en la confrontación y la resignificación de representaciones estigmatizantes, asociadas al pasado, a fin de configurar otras nuevas que buscan legitimar la oficialización de esta lengua. Por ejemplo, en relación con el primer eje, coexisten representaciones de la lengua guaraní como "lengua vulgar o de segunda, idioma de menchos o dialecto de indios y tapes", en oposición a representaciones que la definen como "lengua, idioma", "lengua oficial alternativa", "medio de comunicación y patrimonio o acervo cultural" y "lengua materna de los correntinos". En el segundo eje, se oponen representaciones estigmatizantes del guaraní que lo presentan como el habla de un otro, de un grupo social "descalificado" ("idioma o dialecto de menchos, indios y tapes") y, a su vez, como parte de una identidad plural, del "ser correntino" ("El guaraní es, a los correntinos, nuestra lengua materna", "nos identifica", "Corrientes es guaraní"). En el tercer eje, identificamos la oposición entre representaciones que caracterizan a la escuela como "enemigo" del guaraní, y cuyo rol fue durante mucho tiempo "controlar" y/o "castigar" el empleo de esta lengua. A partir de la sanción de la Ley $\mathrm{N}^{\circ}$ 5598/2004, se busca resignificar este rol, presentándola como instrumento de inclusión social, de promoción de la lengua guaraní y como herramienta para disminuir el analfabetismo. El tejido de representaciones heterogéneas en torno al guaraní, enunciadas por diversos actores sociales, pretende construir y consolidar un contradiscurso hegemónico a favor del rescate, defensa y promoción de esta lengua y busca deslegitimar las políticas lingüísticas vigentes desde la época colonial, cuyo objetivo central era la sustitución del guaraní en favor del castellano.

La sanción de la Ley $\mathrm{N}^{\circ} 5598$ marca un giro importante en las políticas lingüístico-educativas implementadas en el ámbito provincial, ya que pretende regular e institucionalizar una nueva distribución social de las lenguas coexistentes dentro del territorio provincial. Si bien esta propuesta de oficializar el guaraní y la enseñanza del guaraní en las escuelas es aprobada por los hablantes y no hablantes del guaraní en Corrientes, la implementación de esta nueva política plantea numerosos desafíos y dificultades para los planificadores y funcionarios ministeriales, por ejemplo: cómo estandarizar la lengua (variedades), qué grafía adoptar, cómo elaborar material didáctico, cómo instrumentar la formación de docentes y proveer cargos, cómo implementar la enseñanza del guaraní en función de cada situación sociolingüística (como primera lengua o como segunda). 


\section{Biografia}

Mónica Medina es doctora en Letras, becaria posdoctoral de CONICET y docente de la Facultad de Artes, Diseño y Ciencias de la Cultura de la Universidad Nacional del Nordeste.

Adriana Zurlo es doctora en Letras, investigadora de CONICET y docente de la Facultad de Humanidades de la Universidad Nacional del Nordeste.

Lorena Cayré Baito es doctora en Letras, docente investigadora de la Facultad de Humanidades de la Universidad Nacional del Nordeste. 


\section{Q Referencias bibliográficas}

Arnoux, E. y J. Del Valle (2010). Las representaciones ideológicas del lenguaje. Discurso glotopolítico y panhispanismo.Spanish in Context "Ideologías lingüísticas y el español en contexto histórico", 7(1), 1-24.

» Bein, R. (2004). La legislación politico-lingüística en la Argentina.En G. Kremnitz y J. Born (eds) Lenguas, literaturas y sociedad en la Argentina (pp. 41-50). Viena: Praesens.

» Bein, R. (2010a). Las lenguas como fetiche. Recuperado el 17/09/2020 de: http://www. scribd. com/doc/7319552/Roberto-Bein-Las-Lenguas-Como-Fetiche

" Bein. R. (2010b). Los meandros de la política lingüística argentina en relación con las lenguas extranjeras en las leyes generales de Educación. En E. Arnoux y R. Bein (comps.), La regulación política de las prácticas lingüísticas (pp. 307-328). Buenos Aires: Eudeba.

》 Briones, C. (comp.)(2005). Formaciones de alteridad: contextos globales, procesos nacionales y provinciales. En Cartografías Argentinas. Políticas indigenistas y formaciones provinciales de alteridad(pp. 9-36). Buenos Aires: Antropofagia.

》Censabella, M.2009. Chaco ampliado. En I. Sichra (ed.),Atlas sociolingüístico de pueblos indígenas en América Latina. Tomo I (pp. 143-226). Cochabamba: UNICEF; FUNPROEIB Andes. Recuperado el 17 de septiembre del 2020 de https://www.unicef. org/lac/media/9791/file/PDF\%20Atlas\%20sociolinguistico\%20de\%20pueblos\%20 ind\% 3 \%ADgenas\%20en\%20ALC-Tomo\%201.pdf

"Cerno, L.2011. Descripción fonológica y morfosintáctica de una variedad de la lengua guaraní hablada en la provincia de Corrientes (Argentina) [Tesis doctoral]. Facultad de Humanidades y Artes, Universidad Nacional de Rosario, Rosario, Argentina. Recuperado dehttp://www.etnolinguistica.org/tese:cerno-2011

" Dietrich, Wolf. 2002. "Guaraní criollo y guaraní étnico en Paraguay, Argentina y Brasil”. In M. Crevels, S. Van del Kerde, S. Meira \& H. Van del Voort (eds). Current Studies On South American Languages. Leiden: Research School, CNWS, Universiteit Leiden, 31-41.

» Gandulfo, C., Miranda, M., Rodríguez, M. y Soto, O. (2015). El guaraní correntino. En S. Hirsch y A. Lazzari(dirs.), Pueblos Indígenas en la Argentina. Historia, culturas, lenguas y educación (Fascículo 15, pp. 29-50). Ciudad Autónoma de Buenos Aires: Ministerio de Educación y Deportes de la Nación.

» Glozman, M. (Ed.) (2015). Lengua y peronismo: políticas y saberes lingüísticos en la Argentina, 1943-1956: archivo documental. Buenos Aires: Museo del Libro y de la Lengua.

»Insaurralde, Walter (2006). "Sin guaraní, no existe historia en Corrientes". El Litoral, Corrientes. Recuperado 17/9/2020 en: https://www.ellitoral.com.ar/corrientes/2006-717-21-o-o-sin-guarani-no-existe-historia-en-corrientes

"Instituto Nacional de Estadística y Censos (2010). Censo Nacional de Población, Hogares y Viviendas.Buenos Aires.

» Jodelet, D. (1993). La representación social: fenómenos, concepto y teoría.En S. Moscovici (ed.),Psicología Social II(pp. 469-494). Buenos Aires: Paidós.

» López, E. (2013). “Del dicho al hecho...”. Desfases crecientes entre políticas y prácticas en la Educación intercultural bilingüe en América Latina. Páginas y signos. Revista de Lingüistica y Literatura, 9, 11-78.

》 López García, M. (2015). Nosotros, vosotros, ellos. Representaciones de la lengua nacional en los manuales escolares. Buenos Aires: Miño y Dávila. 
" Maeder, E. J. y Gutiérrez, R. (1994). Atlas histórico y urbano del nordeste argentino: Pueblos de indios y misiones jesuíticas (siglos XVI-XX). Primera parte (Vol. 2). Resistencia: Instituto de Investigaciones Geohistóricas.

" Melià, B. (1992). La lengua guaraní del Paraguay. Madrid: Mapfre.

» Ministerio de Educación de Corrientes (2017). Asaje. Libro para docentes. Corrientes: Dirección de Educación Intercultural Bilingüe.

»Poenitz, A. (2012). Mestizo del Litoral. Sus modos de vida en Loreto y San Miguel. Corrientes: Gobierno provincial de Corrientes.

" Rodrigues, Aryon Dall'Igna. 1984/1985. "Relações Internas na Familia Linguística TupíGuaraní", Universidad de São Paulo, Revista de Antropología, 27/28, pp. $33-53$.

»Walsh, C. (2010). “Interculturalidad crítica y educación intercultural”. En: J. Viaña, L. Tapia y C. Walsh, (eds.), Construyendo Interculturalidad Crítica (pp. 75-96). Bolivia: Instituto Internacional de Integración del Convenio Andrés Bello. 